\title{
Efecto de la Cocción en la Concentración de Ciprofloxacina en Camarones de Cultivo
}

\author{
Luis E. Guzmán ${ }^{*}$, Clemente Granados y Diofanor Acevedo \\ Universidad de Cartagena, Facultad de Ingeniería, Departamento de Ingeniería de Alimentos, Avenida el \\ Consulado, Calle 30 No. 48-152. Cartagena, Bolívar-Colombia (e-mail: Iguzmanc1@unicartagena.edu.co) \\ *Autor a quien debe ser dirigida la correspondencia
}

Recibido May. 17, 2013; Aceptado Jul. 17, 2013; Versión final recibida Jul. 26, 2013

\begin{abstract}
Resumen
Se ha evaluado el efecto de la cocción sobre la concentración de ciprofloxacina acumulada en camarones utilizando cromatografía liquida de alta resolución. La ciprofloxacina se utiliza para controlar las enfermedades bacterianas que afectan al camarón de cultivo. Sin embargo, poco se conoce acerca de la estabilidad del antibiótico en camarones sometidos a cocción. Los camarones crudos tuvieron una concentración de $6.60 \mu \mathrm{g} / \mathrm{L}$. Los camarones sin vena y estómago sometidos a cocción a $75^{\circ} \mathrm{C}$ presentaron $5 \mu \mathrm{g} / \mathrm{L}$, mientras que a temperaturas superiores no se detectó presencia del antibiótico. Los camarones con vena y estómago sometidos a cocción a 75,95 y $105^{\circ} \mathrm{C}$, presentaron ciprofloxacina a las tres temperaturas, y la concentración disminuyó con el aumento de la temperatura. Se concluye que a temperaturas superiores a $75^{\circ} \mathrm{C}$ y la eliminación de la vena y estómago elimina la ciprofloxacina del camarón de cultivo.
\end{abstract}

Palabras clave: vibriosis, ciprofloxacina, cromatografía, camarón, cocción.

\section{Effect of Cooking in the Concentration of Ciprofloxacin in Shrimp Culture}

\begin{abstract}
The effect of cooking on the concentration of ciprofloxacin accumulated in shrimp was evaluated using high resolution liquid chromatography. Ciprofloxacin is used to control bacterial diseases affecting farmed shrimp. However, little is known about the stability of the antibiotic in shrimp subjected to cooking. Raw shrimp had a concentration of $6.60 \mathrm{mg} / \mathrm{L}$. Prawns without stomach and vein cooked at $75{ }^{\circ} \mathrm{C}$ had $5 \mathrm{ug} / \mathrm{L}$, whereas at higher temperatures the presence of the antibiotic was not detected. Shrimp with stomach and vein cooked at 75,95 and $105{ }^{\circ} \mathrm{C}$, showed ciprofloxacin at the three temperatures, and concentration decreased with increasing temperature. It is concluded that at temperatures above $75{ }^{\circ} \mathrm{C}$ and removing vein and stomach ciprofloxacin can be eliminated from farmed shrimp.
\end{abstract}

Keywords: vibriosis, ciprofloxacin, chromatography, shrimp, cooking. 


\section{INTRODUCCION}

La existencia de enfermedades bacterianas con implicaciones económicas para la industria acuícola, ha demandado el uso de antimicrobianos en la prevención y tratamiento de estas enfermedades (Fortt et al. 2007). El cultivo de camarón ha mostrado un marcado incremento en la presencia de enfermedades infecciosas y no infecciosas que pueden ocasionar la pérdida de las cosechas, con alta densidad de población (Galaviz et al. 2007). Con la finalidad de contrarrestar el impacto negativo de estas enfermedades se han empleado diferentes tratamientos donde las quinolonas representan el mayor grupo de antibióticos sintéticos ampliamente utilizados como profilácticos y/o quimioterapéuticos e indicados para el tratamiento de varias especies de bacterias como la vibriosis (Escobar et al. 2010), enfermedad bacteriana más frecuente y que afecta tanto la fase larvaria del camarón como la de crecimiento y es considerada la principal causa de mortalidad (Flores et al. 2012; Páez et al. 2003). Esto ha hecho necesario el empleo de antibióticos (Xu et al. 2006; Soto et al. 2006). Sin embargo, el uso excesivo de estos compuestos en el cultivo de camarón puede producir resistencia bacteriana a antimicrobianos (Wang et al. 2004; Cabello, 2004), además de tener implicaciones negativas para la salud humana y animal y para el medio ambiente (Fortt et al. 2007).

La ciprofloxacina una fluoroquinolona, es un antibiótico que actúa contra las bacterias Gram negativas aerobias, incluyendo patógenos entéricos como Pseudomonas y Serratia marcescens y a patógenos Gram positivos, aun cuando éstos hayan desarrollado resistencia a otros antibióticos, incluso a la penicilina (Xu et al. 2006; Fang et al. 2007). No es activo contra bacterias anaerobias y puede utilizarse ocasionalmente, en combinación con otros antibacterianos en el tratamiento de infecciones causadas por mico bacterias (Fang et al. 2007; Banerjee et al. 2007). En relación a su mecanismo de acción, los efectos antibacterianos de la ciprofloxacina se deben a la inhibición de la topoisomerasa IV y la DNA-girasa, interrumpiendo la multiplicación celular bacteriana (Espinosa et al. 2011).

Uno de los factores más importantes para la degradación de los antibióticos en los tejidos, es el tiempo de cocción; por ejemplo, la degradación de OTC en músculo de pavo requirió más de 60 min (O'Brien et al. 1981). Sin embargo, Huang et al. (1997) probaron que la aplicación de tratamientos térmicos como el freído $\left(190^{\circ} \mathrm{C}\right.$ por $\left.7-10 \mathrm{~min}\right)$ y el horneado $\left(190^{\circ} \mathrm{C}\right.$ por $\left.45 \mathrm{~min}\right)$ en filetes de bagre que fueron alimentados con dietas conteniendo OTC durante 10 días, no fue suficiente para eliminar los residuos de este antibiótico. Uno de los problemas potenciales capaces de limitar la comercialización del camarón cultivado, es la presencia de residuos de antibióticos en los tejidos comestibles. Esto debido a la frecuente administración de antibióticos en los cultivos de camarón para contrarrestar las enfermedades bacterianas que afectan a los organismos (Bermúdez et al. 2012). La presencia de antibióticos en los tejidos comestibles puede convertirse en un serio problema de salud, debido a las reacciones de hipersensibilidad que pueden causar. Además, de contribuir a la generación de bacterias resistentes y ocasionar problemas de comercialización debido al incumplimiento en las regulaciones establecidas en distintos países (Bermúdez et al. 2012). Considerando lo anterior, el objetivo de este trabajo fue cuantificar los niveles de ciprofloxacina en camarón de cultivo (Litopenaeus vannamei) después de ser sometido a cocción a diferentes temperaturas.

\section{MATERIALES Y MÉTODOS}

\section{Procedencia de la muestra}

Se trabajó con muestras de camarón (L. Vannamei), procedentes de una finca de cultivo acuícola ubicada en Puerto Badel (Bolívar-Colombia), en la cual se recolectaron muestras en cinco puntos diferentes (extremos y centro de la piscina) hasta completar $300 \mathrm{~g}$.

\section{Reactivos y materiales}

Los solventes empleados en la extracción de la ciprofloxacina, fueron; ácido oxálico, ácido etilén-diaminotetra-acético (EDTA), butilhidroxianisol (BHA) y butilhidroxitolueno (BHT). Los solventes y estándares empleados en cromatografía fueron de alta pureza (Aldrich Chemical Company). Los papeles de filtro grado 1 y las columnas de fase solida (C18) de 400 y 1000 mg se obtuvieron de la casa comercial Baker Inc. Los reactivos utilizados durante el análisis fueron: Fosfato Básico de Sodio, Ácido Cítrico, Acido Oxálico, Metanol, Agua destilada.

\section{Preparación de soluciones}

Las soluciones empleadas durante la cuantificación de la Ciprofloxacina fueron: Mcllvaine buffer $\mathrm{pH} 4,0$ : $28,4 \mathrm{~g} \mathrm{Na}_{2} \mathrm{HPO}_{4}$ anhidro (grado reactivo)/1L en agua. Se diluyó la solución con agua destilada hasta el aforo y se mezcló. Se colocaron $21 \mathrm{~g}$ de ácido cítrico en un frasco volumétrico de 1 litro y se diluyó con agua 
destilada hasta completar 1 litro. Luego se mezcló bien y se combinó 1 litro de las soluciones de ácido cítrico con $625 \mathrm{~mL}$ de la solución de fosfato sódico en un balón aforado de 2 litros. Se ajustó a pH $4.0 \pm 0.05$. Estas soluciones se prepararon semanalmente. Mcllvaine buffer-Solución de EDTA: Se Ajustó Mcllvaine buffer de forma que contuviera $0,1 \mathrm{M}$ de etilen-diamino del ácido tetracético sal sódica. A 1,625 litros de buffer Mcllvaine $\mathrm{pH} 4,0$, se añadió $60,5 \mathrm{~g}$ de EDTA. $2 \mathrm{H}_{2} \mathrm{O}$ disódico. Se mezcló hasta que se disolvió. Ésta se preparó semanalmente.

Para la solución metanólica de ácido oxálico $0,01 \mathrm{M}$ : se pesaron 1,26 g de ácido oxálico dihidratado en un frasco volumétrico de 1 litro, se disolvió y se llevó a volumen con metanol, esta solución se preparó diariamente. La solución acuosa de ácido oxálico $0,01 \mathrm{M}$ : se disolvió $1,26 \mathrm{~g}$ de ácido oxálico dihidratado en agua destilada dentro de un frasco volumétrico de 1 litro. Se diluyó a volumen y se mezcló.

\section{Preparación de la muestra}

La muestra de $300 \mathrm{~g}$ de camarones se dividió en tres ( $\mathrm{A}, \mathrm{B}$ y $\mathrm{C}$ ); a todas las muestras se les retiró la cabeza, cola, patas y caparazón; a las muestras A y B se les retiraron además la vena y el estómago teniendo cuidado de no dejar residuos, ya que podían provocar interferencias en el análisis debido a que el antibiótico que es suministrado junto con el alimento se acumula en el tracto digestivo. La muestra A conformada por camarones crudos se utiliza como patrón de referencia; las muestras B y C son sometidas a cocción.

\section{Tratamiento de cocción}

Se utilizaron $300 \mathrm{~mL}$ de agua calentada a temperaturas de 75,95 y $105^{\circ} \mathrm{C}$ en una placa de calentamiento (VWR Scientific, modelo 220) y se introdujeron las muestras B y C por 3 minutos tiempo al cabo del cual presentaron un color rosado y una textura del músculo suave, con una temperatura interna de $\pm 63^{\circ} \mathrm{C}$.

\section{Extracción del antibiótico}

Se pesaron $6,82 \mathrm{~g}$ de cada una de las muestras previamente limpias por triplicado, se adicionaron $20 \mathrm{~mL}$ de la solución extrayente (Solución Mcllvaine-EDTA) y se agitó en un zonicador durante 2 minutos, se traspasó a un tubo de centrífuga de $12 \mathrm{~mL}$ y se centrifugó a $2500 \mathrm{rpm}$ durante 30 minutos, posteriormente se decantó la solución en un vaso de precipitados. Cada una de las muestras se trabajó por triplicado, luego se filtró utilizando un embudo buchner y papel de filtro Whatman 41. El filtrado de cada muestra se almacenó de manera individual para su posterior purificación en columna de fase sólida.

\section{Purificación en fase solida}

Se empleó una columna de extracción de fase solida reversa empacada con 400 y 1000 mg de C18 con capacidad de 3 y $6 \mathrm{~mL}$ respectivamente

\section{Acondicionamiento}

Se pasaron $10 \mathrm{~mL}$ de metanol y seguidamente $10 \mathrm{~mL}$ de agua. Sin dejar secar la columna se adicionan 10 $\mathrm{mL}$ de extracto filtrado en correspondencia con la columna empleada de $400 \mathrm{mg}$ o $1000 \mathrm{mg}$ respectivamente. Posteriormente se adicionaron $5 \mathrm{~mL}$ de ácido oxálico y se recolectó en un tubo de ensayo. Todo este proceso se realizó a un flujo lento para garantizar la recuperación de la sustancia absorbida en la columna. Todo el eluato purificado se re-envasó en unos recipientes y se concentró a temperatura ambiente hasta sequedad, al día siguiente se le adiciono $1 \mathrm{~mL}$ de metanol a cada una de las muestras y después se re-envasaron para que se siguieran concentrando hasta realizar el análisis cromatografico.

\section{Análisis cromatográfico}

Se empleó un cromatógrafo líquido Bas, con detector UVIVIS y detector de fluorescencia wáter 474 inyección manual y una columna $\mathrm{C} 18(150 \times 4.0 \mathrm{~mm}, 5 \mu \mathrm{m}$ de tamaño de partícula marca phenomenex), como fase móvil se empleó una mezcla de ácido oxálico 0,13 \%; acetonitrilo; metanol (60: 30: $10 \mathrm{v} / \mathrm{v})$. El flujo fue $1,0 \mathrm{~mL} / \mathrm{min}$ y se aplicaron $10 \mathrm{~mL}$ de la muestra previamente filtrada.

\section{Análisis estadístico}

Para determinar diferencias estadísticas, se utilizó el programa Minitab-16 (Statiscal Softwarwe, USA 2011). Se determinó la desviación estándar (SD), y el coeficiente de variación (\%CV) el cual es la medida de la relación entre la desviación y la media. 


\section{RESULTADOS Y DISCUSIÓN}

Los camarones crudos de la muestra A presentaron una concentración de 6,60 $\mathrm{\mu g} / \mathrm{L}$ con un nivel de confianza del $95 \%$. Estos resultados fueron inferiores al límite de residuo máximo establecido por la Unión Europea de $100 \mu \mathrm{g} / \mathrm{kg}$. En la Tabla1, se presentan las concentraciones de ciprofloxacina de la muestra B, que corresponde a la de camarones sin vena y estómago, los cuales fueron sometidos a cocción a las temperaturas de 75,95 y $105^{\circ} \mathrm{C}$. Los camarones sin vena y estomago sometidos a $75^{\circ} \mathrm{C}$ presentan $5 \mu \mathrm{g} / \mathrm{L}$ de ciprofloxacina, superior a los reportados por Xu et al. (2006), mientras que a las temperaturas de 95 y $105^{\circ} \mathrm{C}$ no se detectó la presencia de ésta sustancia, por lo cual se puede indicar que la cocción a temperaturas superiores a $95^{\circ} \mathrm{C}$ elimina la ciprofloxacina en camarones.

Tabla 1: Concentraciones de ciprofloxacina en camarones sin venas y estómagos tratados en cocción

\begin{tabular}{|l|c|c|c|}
\hline & Cocido a $75^{\circ} \mathrm{C}$ & Cocido a $95^{\circ} \mathrm{C}$ & Cocido a $105{ }^{\circ} \mathrm{C}$ \\
\hline & Concentración $\mu \mathrm{g} / \mathrm{L}$ & Concentración $\mu \mathrm{g} / \mathrm{L}$ & Concentración $\mu \mathrm{g} / \mathrm{L}$ \\
\hline Media & 5,0 & NP & NP \\
\hline SD & 0,30 & NP & NP \\
\hline$\%$ CV & 6,07 & NP & NP \\
\hline
\end{tabular}

La Tabla 2 muestra las concentraciones de ciprofloxacina en camarón (L. vannamei) con vena y estomago en cocción a diferentes temperaturas, las cuales presentan diferencias. Se puede observar que con el aumento de la temperatura disminuye la concentración en el camarón, resultados similares a los obtenidos por O'Brien et al. 1981. A todas las temperaturas de cocción los camarones presentan ciprofloxacina, debido a que en el estómago se absorbe o almacena en mayor cantidad el antibiótico que es ingerido. Sin embargo todas las concentraciones están por debajo del límite máximo residual permitido de $100 \mu \mathrm{g} / \mathrm{kg}$ por la Comunidad Económica Europea.

Tabla 2: Concentraciones de ciprofloxacina en camarones con vena y estomago tratados térmicamente

\begin{tabular}{|l|l|l|l|}
\hline & Cocido a $75^{\circ} \mathrm{C}$ & Cocido a $95^{\circ} \mathrm{C}$ & Cocido a $105{ }^{\circ} \mathrm{C}$ \\
\hline & Concentración $\mu \mathrm{g} / \mathrm{L}$ & Concentración $\mu \mathrm{g} / \mathrm{L}$ & Concentración $\mu \mathrm{g} / \mathrm{L}$ \\
\hline Media & 4,91 & 0,41 & 0,14 \\
\hline SD & 0,03 & 0,01 & 0,01 \\
\hline$\% \mathrm{CV}$ & 1,28 & 1,26 & 1,59 \\
\hline
\end{tabular}

Xu et al. (2006) informaron que suministraron una dosis de $50 \mathrm{mg} / \mathrm{kg}$ de enrofloxacina y ciprofloxacina al camarón chino durante 7 días, y observaron que la acumulación en musculo de enrofloxacina y ciprofloxacina respectivamente fue de $1,68 \mu \mathrm{g} / \mathrm{g}$ y $0,07 \mu \mathrm{g} / \mathrm{g}$, y el tiempo para eliminarse en el músculo fue de 12 y 3 días respectivamente.

\section{CONCLUSIONES}

La cocción es importante en el procesamiento del camarón para mantener una buena calidad, y que así sean aptos para el consumo humano. Con este estudio se confirma que la cocción a temperaturas superiores a $75^{\circ} \mathrm{C}$, y la separación de la vena y estómago del camarón eliminan la ciprofloxacina, evitando la posibilidad de representar un riesgo a la salud de consumidores de camarón.

\section{REFERENCIAS}

Banerjee, S. y tres autores, Comparation of four antibiotics with indigenous marine Bacillus spp. in controlling pathogenic bacteria from shrimp and Artemia, Journal of Fish Diseases, 30(7), 383-389 (2007).

Bermúdez, C. y otros tres autores, Efecto del congelado y cocinado sobre residuos de oxitetraciclina en camarón de cultivo, Revista Biotécnia, 13(13), 12-21 (2012)

Cabello, F., Antibióticos y acuicultura en Chile: consecuencias para la salud humana y animal, Revista Médica de Chile, 132(8), 1001-1006 (2004). 
Escobar, A., y otros cuatro autores, Aplicación del HPLC en el establecimiento del período de latencia de la oxitetraciclina en músculo de camarón (Litopenaeus vannamei) en un sistema de producción semi-intensivo en Cuba, Rev. Salud Anim., 32(2), 97-105 (2010).

Espinosa, A., y tres autores, Efecto del congelado y cocinado sobre residuos de oxitetraciclina en camarón de cultivo, Revista de Ciencias Biológicas y de la Salud. 13(3), 12-21 (2011).

Fang, W. y otros cinco autores, Pharmacokinetics and tissue distribution of enrofloxacin and its metabolite ciprofloxacin in Scylla serrata following oral gavage at two salinities, Aquaculture, 272(1-4), 180-187 (2007).

Flores, B.M. y otros cinco autores, Accumulation and Elimination of Enrofloxacin and Ciprofloxacin in Tissues of Shrimp vannamei under Laboratory and Farm Conditions, ISRN pharmaceutics, 2012,374212 (2012).

Fortt, A., Cabello, F. y Buschmann, A., Residuos de tetraciclina y quinolonas en peces silvestres en una zona costera donde se desarrolla la acuicultura del salmón en Chile, Rev. Chil. Infect., 24(1), 14-18 (2007).

Galaviz, S.L. y otros tres autores, Patógenos que disminuyen la calidad del camarón de cultivo, Revista Salud Pública y Nutrición, 12, 419-425 (2007).

Huang, T.S. y tres autores, Determination of oxytetracycline in raw and cooked channel catfish by capillary electrophoresis, J. Agric. Food Chem. 45(7), 2602-2605 (1997).

O’Brien, J.J., Campbell, N. y Conagham T., Effect of cooking and cold storage on biologically active antibiotic residues in meat, Journal Hygiene Cambridge 87(3), 511-523 (1981).

Williams, R., Bell, T.A. y Donald, V., Shrimp antimicrobial testing: II. Toxicity testing and safety determinations for twelve antimicrobials with penaeus shrimp larvae, Journal of Aquatic Animal Health, 4(4), 262-270 (2002).

Xu, W. y otros cuatro autores, Residues of enrofloxacin, furazol idone and their metabolites in Nile tilapia (Oreochromis niloticus). Aquaculture, 254(1-4), 1-8 (2006). 
